\title{
Intraoperative Monitoring of the Somatosensory Evoked Potentials and Cerebral Blood Flow During Aneurysm Surgery
}

-Safety Evaluation for Temporary Vascular Occlusion-

\author{
Kazuo MizoI and Takashi YoshimoTo* \\ Department of Neurosurgery, Kohnan Hospital, Sendai; *Division of Neurosurgery, \\ Institute of Brain Diseases, Tohoku University School of Medicine, Sendai
}

\begin{abstract}
Somatosensory evoked potentials (SEPs) and cerebral blood flow (CBF) were monitored during temporary vascular occlusion in 67 aneurysm operations to evaluate the usefulness of SEP as an indicator for cerebral ischemia. The SEP $\mathrm{N}_{20}$ component completely disappeared during temporary vascular occlusion in 24 cases, 23 of which demonstrated complete recovery following recirculation and had no postoperative neurological sequelae. The only one with postoperative sequelae demonstrated rapid, within 1 minute, loss of $\mathrm{N}_{20}$ followed by no recovery. Another eight cases showed prolongation of central conduction time during vascular occlusion and had no postoperative sequelae. The SEP $\mathrm{N}_{20}$ attenuation reflected the CBF reduction in the middle cerebral artery (MCA) territory during MCA occlusion. However, CBF changes in the internal carotid artery (ICA) territory during ICA occlusion greatly varied. No detectable changes in SEP were found during anterior cerebral artery occlusion for anterior communicating artery aneurysms. This study indicates that intraoperative SEP monitoring is useful to detect ischemia in the MCA territory and that rapid disappearance of the $\mathrm{N}_{20}$ component is a danger signal.
\end{abstract}

Key words: cerebral aneurysm, temporary occlusion, intraoperative monitoring, somatosensory evoked potential, cerebral blood flow

\section{Introduction}

Intraoperative aneurysmal rupture can be prevented by first temporarily occluding the major cerebral vessels and then treating the aneurysmal neck. ${ }^{26-291}$ This technique has increasingly been used recently because of its effectiveness. ${ }^{2,6,9,14)}$ The principal problem with temporary vascular occlusion is the possibility of induced ischemic brain damage. Various techniques are available to protect the brain, including use of the Sendai cocktail containing mannitol, vitamin $\mathrm{E}$, and phenytoin.

Our experimental ${ }^{1,25}$ and clinical investigations $^{27-29)}$ have shown that this agent, given intravenously, allows occlusion of any combination of cerebral blood vessels at any location for up to 40 minutes without resultant brain damage, if the occlu-

Received June 20, 1988;

Accepted March 29, 1989 sion is completed within 100 minutes after the administration. However, experimental work has also shown that lower tolerance to tempotary vascular occlusion results in severer ischemia. ${ }^{11,16)}$ In addition, decreases in cerebral blood flow (CBF) caused by occlusion differ with the sites of occlusion and the individuals, so the allowable duration of temporary vascular occlusion will vary. In our early study, ${ }^{28)}$ postoperative neurological sequelae occurred in only four of 384 cases $(1 \%)$ receiving mannitol administration to protect the brain, and all four underwent relatively short vascular occlusion $(5-20 \mathrm{~min})$.

Cerebral function monitoring during neurosurgical procedures is used more frequently today. Electroencephalographic (EEG) monitoring during temporary occlusion in carotid endarterectomy has been performed..$^{3,5,20,22-24)}$ Since the somatosensory evoked potentials (SEPs) accurately reflect cerebral ischemia and can be evaluated quantitatively more 
easily than EEG, SEP monitoring has also been used during temporary occlusion in both carotid endarterectomy and aneurysm surgery. $4,7,10,12,15,17,18,21)$ We therefore studied SEP and CBF changes during aneurysm surgery, particularly during temporary vascular occlusion, and the indications for subsequent ischemic brain damage.

\section{Clinical Materials and Methods}

Intraoperative SEP monitoring was possible in 61 of the 86 cases undergoing direct aneurysm surgery between July, 1986 and June, 1987. Five cases had multiple aneurysms, giving a total of 67 aneurysms in this study. Twenty aneurysms were on the middle cerebral artery (MCA), 24 on the internal carotid artery (ICA), 20 on the anterior communicating artery (AcomA), and three on the vertebrobasilar arterial system (VBA). Preoperatively, the Hunt and Kosnik ${ }^{8}$ grades of the patients were 0 in one, 1 in five, 2 in 38, 3 in 13, and 4 in four. Most operations were performed in the acute stage, with 21 cases operated on within 24 hours of ictus. Temporary vascular occlusion was performed in all cases. A summary of the sites and durations is given in Table 1.

The aneurysm site controlled whether the feeding or both the feeding and draining arteries were occluded. However, the present study only examined the occlusion of the feeding arteries. There were no significant differences in the occlusion times with aneurysm site, and the mean occlusion time was $20 \pm 10$ minutes.

SEPs were monitored with a Neuropak 8 system (Nihon Kohden Corp., Tokyo). In most cases, the
Table 1 Site and duration of temporary vascular occlusion for each aneurysm site

\begin{tabular}{|c|c|c|c|c|}
\hline \multirow{2}{*}{$\begin{array}{l}\text { Aneurysm } \\
\text { site }\end{array}$} & \multirow{2}{*}{$\begin{array}{c}\text { No. of } \\
\text { aneurysms }\end{array}$} & \multirow{2}{*}{$\begin{array}{c}\text { Occlusion } \\
\text { site }^{*}\end{array}$} & \multicolumn{2}{|c|}{ Occlusion time (min) } \\
\hline & & & Range & Mean $\pm S D$ \\
\hline $\mathrm{MCA}$ & 20 & $\mathrm{M}_{1}\left(\mathrm{M}_{2}\right)$ & $4-48$ & $20.1 \pm 10.5$ \\
\hline ICA & 24 & ICA $(P \operatorname{com} A)$ & $2-52$ & $18.2 \pm 10.9$ \\
\hline$A \operatorname{com} A$ & 20 & both $A_{1}\left(A_{2}\right)$ & $5-38$ & $21.1 \pm 9.1$ \\
\hline VBA & 3 & $\mathrm{BA}$ or $\mathrm{VA}$ & $21-39$ & $28.5 \pm 7.7$ \\
\hline Total & 67 & & $2-52$ & $20.1 \pm 10.4$ \\
\hline
\end{tabular}

${ }^{*}\left(\right.$ ) indicates with or without. Thus $\mathrm{M}_{1}\left(\mathrm{M}_{2}\right)$ indicates $\mathrm{M}_{1}$ or $\mathrm{M}_{1}+\mathrm{M}_{2}$.

SEPs were evoked by stimulating the median nerve at the wrist, but for AcomA aneurysm cases, the posterior tibial nerve was also stimulated. The stimulation parameters for the median nerve were $10-12 \mathrm{~mA}, 0.2-\mathrm{msec}$ duration, and $4-\mathrm{Hz}$ square waves. A saddle-shaped bipolar stimulator was used to stimulate the bilateral median nerves alternately, and the bilateral SEPs were recorded. The recording electrodes were located at C3' and C4' (international 10-20 system) and the second cervical vertebra (Cv2) and Erb's point. A frontal reference (Fz) was used. The band-pass filters were set to $20-500 \mathrm{~Hz}$ for recording cortical components $\left(\mathrm{N}_{20}\right)$ and to 100 $1500 \mathrm{~Hz}$ for analyzing short-latency components $\left(\mathrm{N}_{14}\right)$. The analysis time was $50 \mathrm{msec}$, and $500 \mathrm{re}-$ sponses were averaged. Following Symon et al. ${ }^{30,32)}$ we have focused on the central conduction time (CCT) and amplitude of the $\mathrm{N}_{20}$ peaks (Fig. 1A). The stimulus parameters for the posterior tibial nerve were $12-15 \mathrm{~mA}, 0.2-\mathrm{msec}$ duration, and $5-\mathrm{Hz}$ square
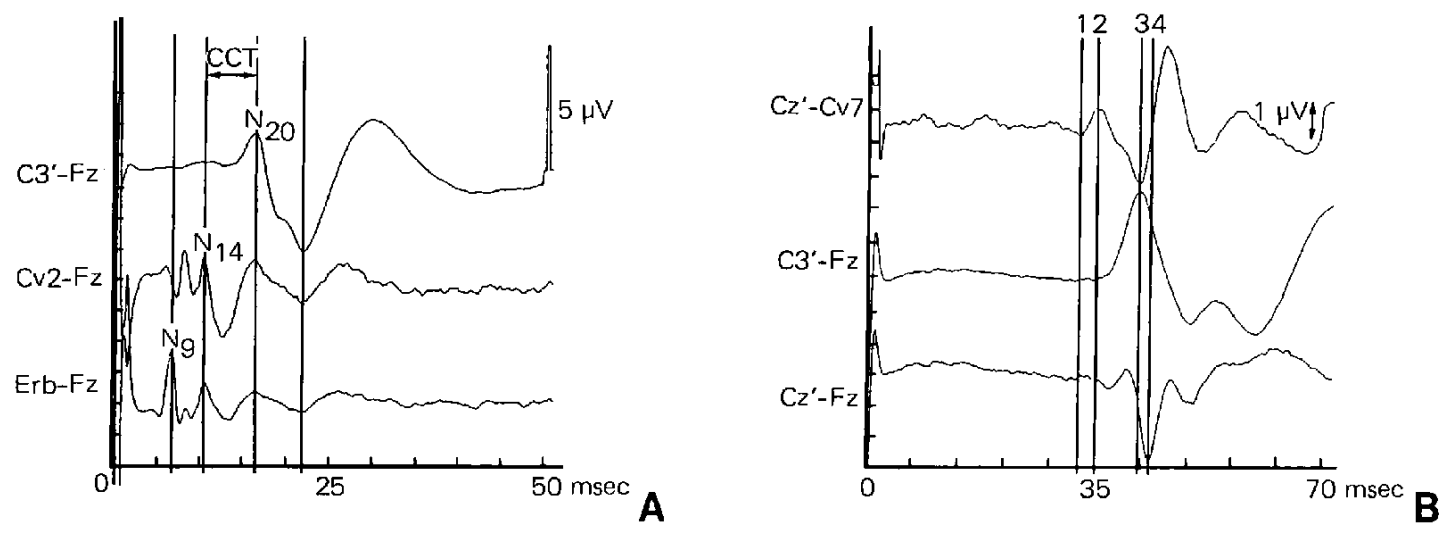

Fig. 1 Intraoperative median nerve (A) and posterior tibial nerve (B) SEP recordings. CCT is defined as the interpeak latency between $\mathrm{N}_{20}$ and $\mathrm{N}_{14}$. Line 1: $\mathrm{P}_{30}$ generated from dorsal column nucleus, line 2: $\mathrm{N}_{34}$ generated from medial lemniscal pathway, lines 3 and $4: P_{38}$ generated from primary sensory cortex. $\mathrm{C}^{\prime}$ : left sensory cortex, $\mathrm{Cv} 2$ : second cervical spinous process, $\mathrm{Cv} 7: 7$ th cervical spinous process, $\mathrm{Cz}^{\prime}: 2 \mathrm{~cm}$ posterior to the $\mathrm{Cz}$, Erb: Erb's point, Fz: frontal vertex. 


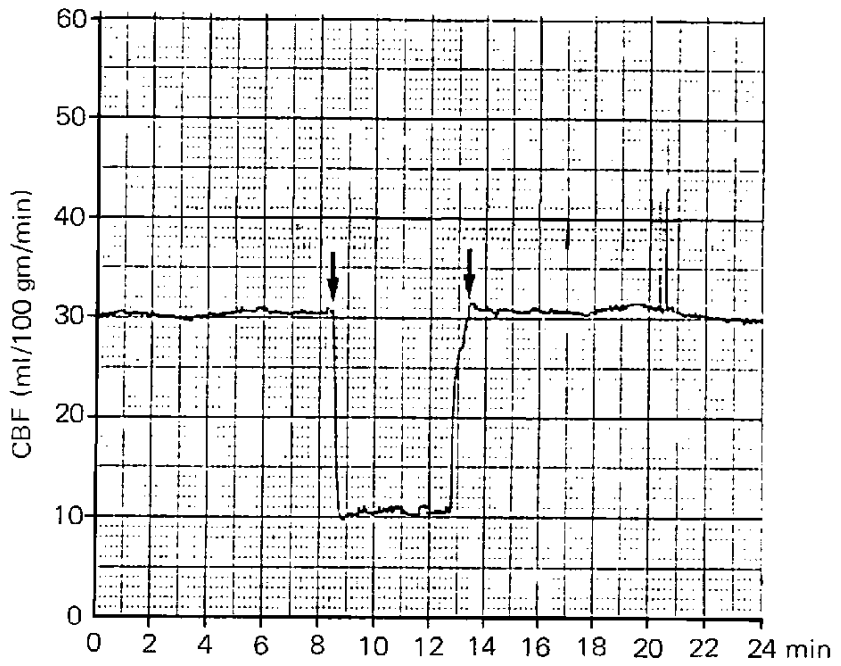

Fig. 2 Intraoperative $\mathrm{CBF}$ monitoring using a thermal diffusion flow probe. In this case, CBF was reduced from 30 to $10 \mathrm{ml} / 100 \mathrm{gm} / \mathrm{min}$ during temporary MCA occlusion (arrows).

waves. The recording and reference electrodes were placed following Urasaki et al. ${ }^{31)}$ The band-pass filter was set to $100-1000$ or $20-500 \mathrm{~Hz}$. The analysis took $70 \mathrm{msec}$, averaging 500-1000 responses (Fig. 1B). SEP monitoring was started after the induction of anesthesia to minimize preoperative stress and continuously recorded before and after temporary vascular occlusion. All results were stored on floppy disks.

CBF measurements used a thermal diffusion flow probe (BTG-III, Biomedical Inc., Kanazawa). ${ }^{13,33)}$ The CBF probe was placed directly on the cortex in the area of interest after opening the dura mater (Fig. 2).

\section{Results}

I. Classification of the SEP changes caused by temporary vascular occlusion

Changes in the median nerve SEPs following temporary occlusion were classified into four grades as shown in Table 2 and Fig. 3A-D. Posterior tibial nerve SEP monitoring only for AcomA aneurysm cases showed no changes, making grading unnecessary (Fig. 3E).

\section{Relationship between SEP changes and aneu- rysm site}

The SEP changes during temporary vascular occlusion with different aneurysm sites are summarized in Table 3.
Fifteen $(75 \%)$ of the $20 \mathrm{MCA}$ aneurysm cases demonstrated Grade 3 SEP changes. The occlusion time in these ranged from 4 to 42 minutes, with a mean of 19.5 minutes. SEP attenuation began 3 to 16 minutes (mean $8.8 \mathrm{~min}$ ) after the start of vascular occlusion. SEP recovery had already occurred by the first postrecirculation measurement in 11 cases. The other four demonstrated signs of recovery within 8 minutes. All the 15 cases eventually showed complete recovery of $\mathrm{N}_{20}$ amplitude and return to the preocclusion level of CCT and had no postoperative neurological sequelae caused by the temporary vascular occlusion. The duration of $\mathrm{N}_{20}$ absence ranged from 2 to 38 minutes (mean $13.3 \mathrm{~min}$ ) (Fig. 4A). The other five MCA aneurysm cases demonstrated lower grade changes and subsequent recovery of the SEPs and had favorable postoperative outcomes.

Eight $(33 \%)$ of the 24 ICA aneurysm cases showed Grade 3 changes. The mean occlusion time was 22.8 minutes. The SEP disappeared at 1-30 minutes (mean $9.5 \mathrm{~min}$ ) from the start of occlusion. After an average of 4.9 minutes of recirculation, seven of the eight cases showed considerable recovery of the SEPs, which were eventually similar to the preocclu-

Table 2 Classification of SEP changes during temporary vascular occlusion

\begin{tabular}{cl} 
Grade & \multicolumn{1}{c}{ Criterion } \\
\hline 0 & no change \\
1 & $<1.0$ msec prolongation of $\mathrm{CCT}$, or \\
& $<50 \%$ decrease in $\mathrm{N}_{20}$ amplitude \\
2 & $\geqq 1.0 \mathrm{msec}$ prolongation of CCT, or \\
3 & $\geqq 50 \%$ decrease in $\mathrm{N}_{20}$ amplitude \\
& loss of $\mathrm{N}_{20}$
\end{tabular}

Table 3 Summary of SEP changes for each aneurysm site

\begin{tabular}{|c|c|c|c|c|}
\hline \multirow{2}{*}{$\begin{array}{c}\text { Aneurysm } \\
\text { site }\end{array}$} & \multicolumn{4}{|c|}{ Grade of SEP changes } \\
\hline & 0 & 1 & 2 & 3 \\
\hline $\mathrm{MCA}$ & $\begin{array}{c}2 \\
(24)\end{array}$ & $\begin{array}{c}1 \\
(6)\end{array}$ & $\begin{array}{c}2 \\
(27.7)\end{array}$ & $\begin{array}{c}15 \\
(19.5 \pm 10.9)\end{array}$ \\
\hline ICA & $(11.8 \pm 6.8)$ & $\begin{array}{c}5 \\
(24.7 \pm 14.0)\end{array}$ & 0 & $\begin{array}{c}8 \\
(22.8 \pm 8.2)\end{array}$ \\
\hline AcomA & $\left(21.1^{20} \pm 9.1\right)$ & 0 & 0 & 0 \\
\hline VBA & $\stackrel{2}{(23.5)}$ & 0 & 0 & $\begin{array}{c}1 \\
(39)\end{array}$ \\
\hline Total & $\begin{array}{c}35 \\
\left(18.5^{ \pm} \pm 9.2\right)\end{array}$ & $\begin{array}{c}6 \\
(21.6 \pm 14.6)\end{array}$ & $\begin{array}{c}2 \\
(27.7)\end{array}$ & $\begin{array}{c}24 \\
(21.4 \pm 10.6)\end{array}$ \\
\hline
\end{tabular}

Mean occlusion time $\pm \mathrm{SD}$ given in parentheses (min). 

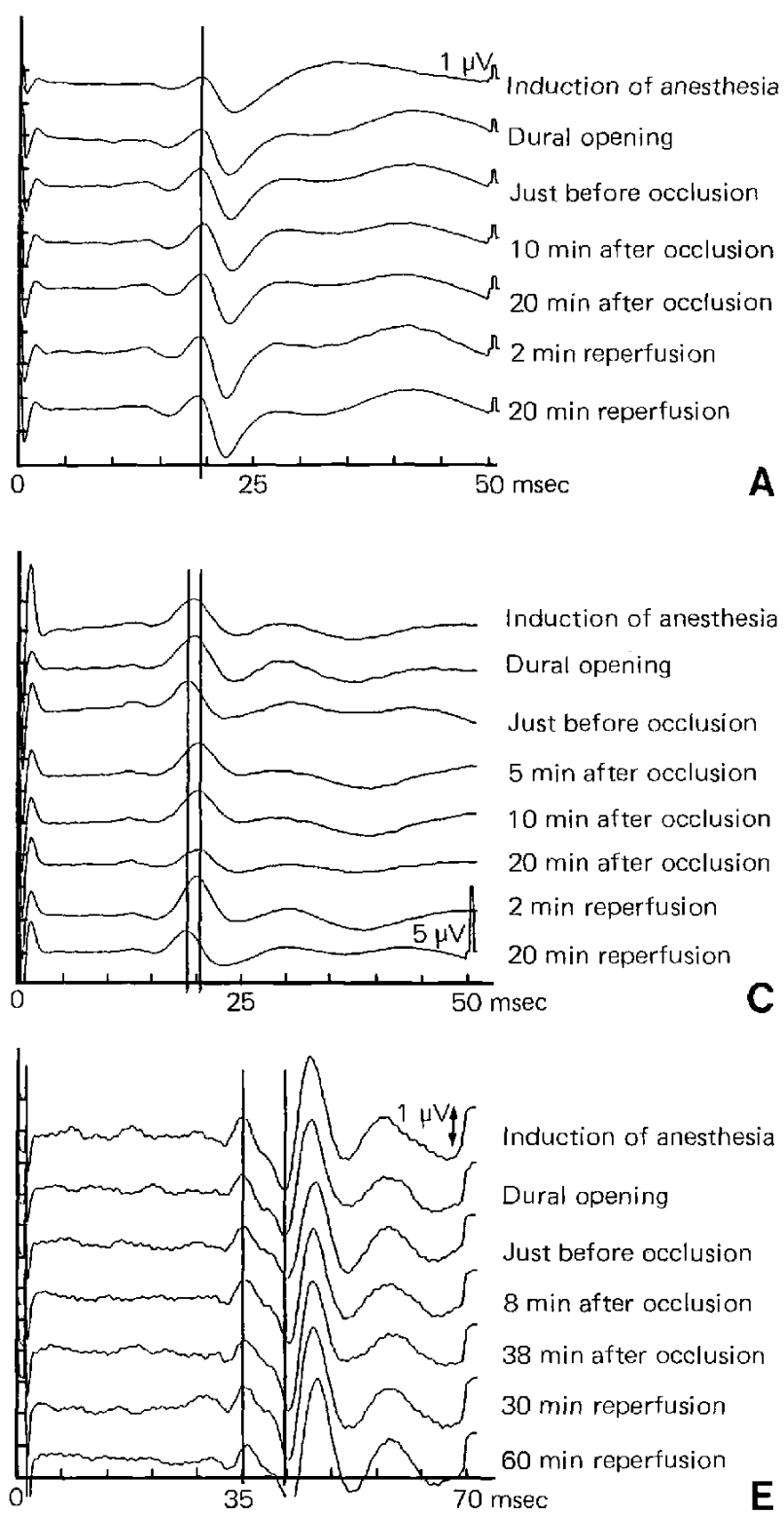

sion level. The duration of SEP attenuation was between 8 and 37 minutes (mean $17.7 \mathrm{~min}$ ). The other one case did not show SEP recovery following recirculation. This was the only case in the series to have permanent postoperative sequelae due to the temporary vascular occlusion (Fig. 4B). Vascular occlusion was relatively short $(17 \mathrm{~min})$, but the SEP was absent immediately following occlusion. The other 16 ICA aneurysm cases showed Grade 1 or 0 changes
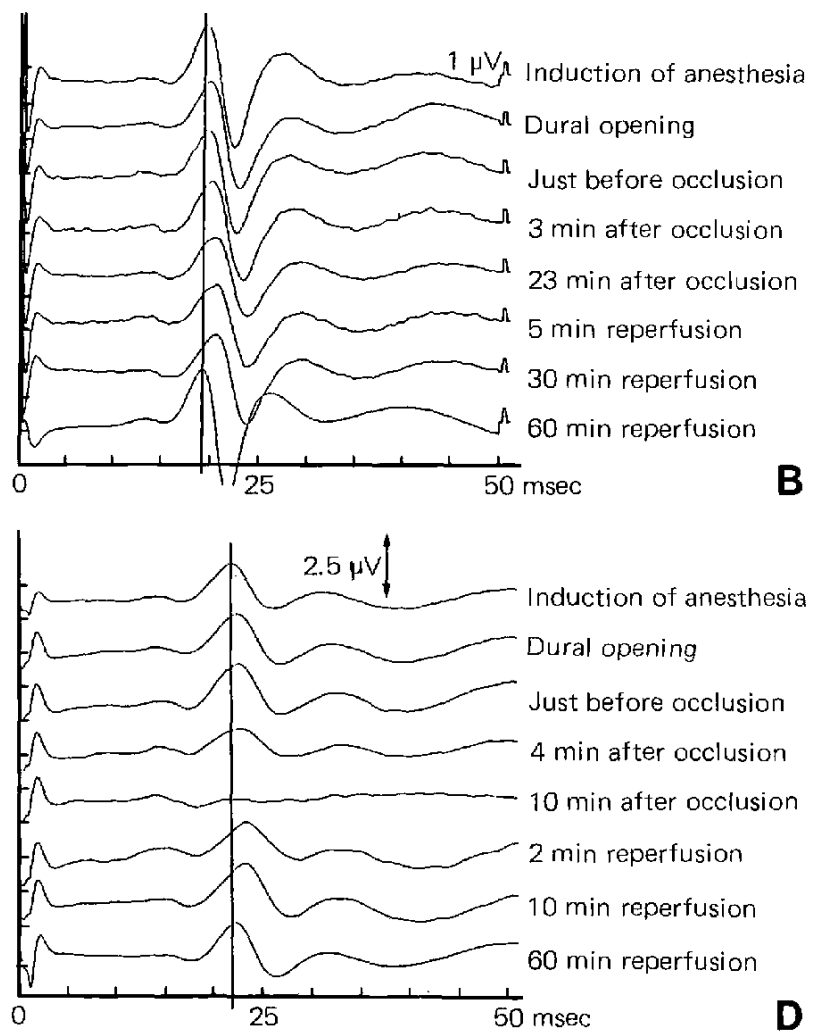

Fig. 3 A: Median nerve SEP changes, Grade 0. In this case, SEP $\mathrm{N}_{20}$ was preserved with no changes in latency and amplitude after 20 minutes of MCA occlusion. B: Median nerve SEP changes, Grade 1. In this case, CCT prolonged from 7.6 to $8.4 \mathrm{msec}$ after temporary occlusion of ICA and returned to the preocclusion level after reperfusion. C: Median nerve SEP changes, Grade 2 . This case showed a prolongation of CCT from 6.0 to $7.0 \mathrm{msec}$ and a reduction in $\mathrm{N}_{20}$ amplitude of more than $50 \%$ of the preocclusion level after temporary MCA occlusion. D: Median nerve SEP changes, Grade 3. In this case, $\mathrm{N}_{20}$ disappeared 10 minutes after MCA occlusion and recovered rapidly following recirculation. E: Posterior tibial nerve SEP changes, Grade 0. All AcomA aneurysm cases examined showed no changes during bilateral ACA occlusion.

and had favorable postoperative courses.

There were no detectable SEP changes among the 20 AcomA aneurysm cases. The SEPs were elicited by median nerve stimulation in 13 cases and by posterior tibial nerve stimulation in seven. None had postoperative sequelae attributable to the temporary vascular occlusion.

There were two cases with vertebral-posterior inferior cerebellar artery aneurysms and only one with 

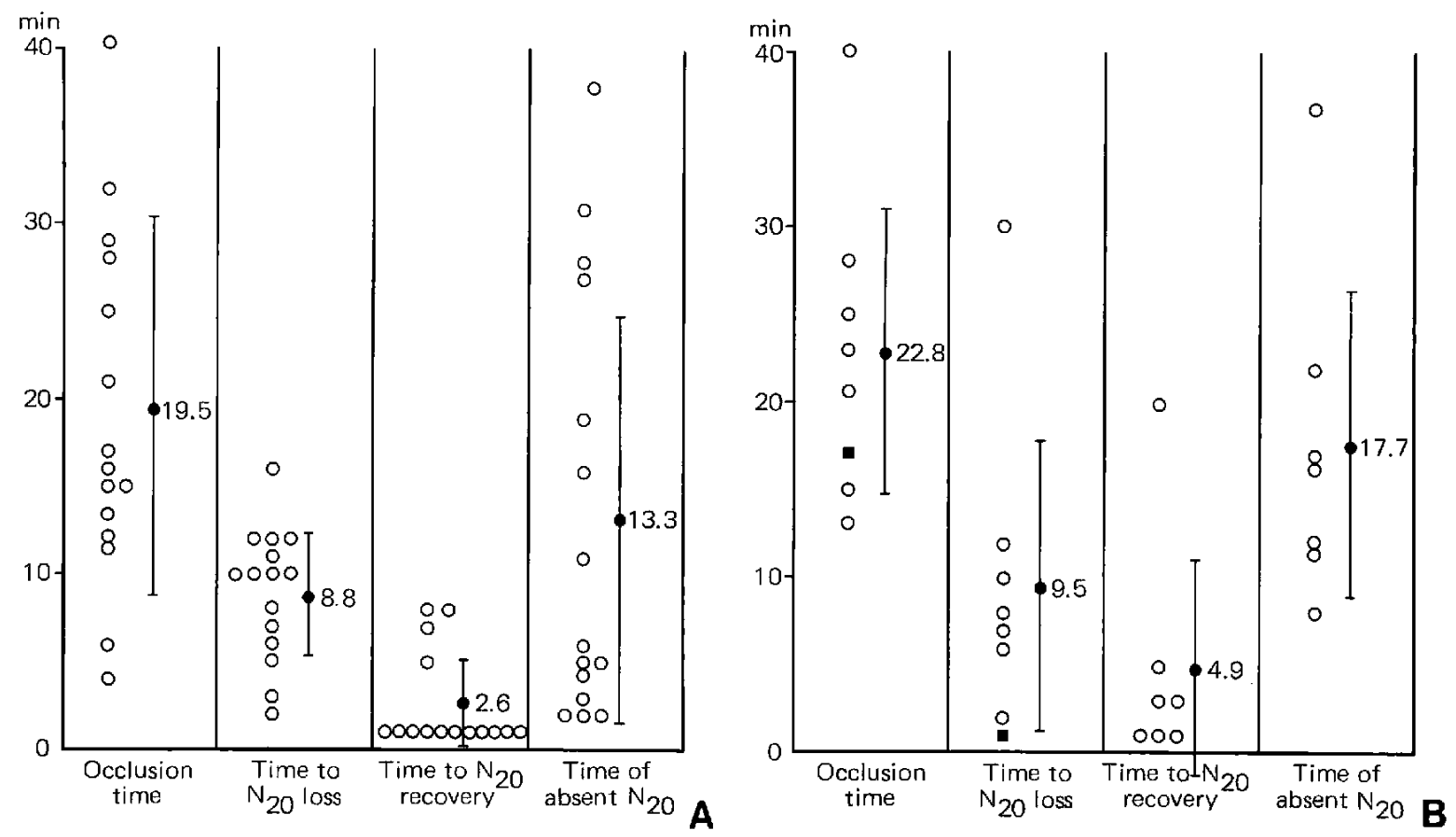

Fig. 4 Occlusion time, time to $\mathrm{N}_{20}$ loss from the start of temporary occlusion, time to $\mathrm{N}_{20}$ recovery from the start of recirculation, and time of absent $\mathrm{N}_{20}$ (occlusion time - time to $\mathrm{N}_{20}$ loss + time to $\mathrm{N}_{20}$ recovery) in cases with Grade 3 SEP changes during MCA occlusion ( $\mathrm{A}, \mathrm{n}=15)$ or ICA occlusion $(B, n=8)$. Each closed circle and bar represent mean \pm SD. $\mathbf{~ : ~ c a s e ~ w i t h ~ p e r m a n e n t ~ d e f i c i t . ~}$

a basilar tip aneurysm. The former two cases showed no changes in the SEP due to the temporary occlusion of the vertebral artery (VA). In the latter one, the basilar artery (BA) and the bilateral posterior cerebral arteries (PCAs) were occluded for 39 minutes. The SEP became attenuated after 7 minutes but recovered immediately following recirculation. No sequelae due to the temporary vascular occlusion were evident postoperatively.

\section{CBF changes during temporary vascular occlu- sion}

Reliable data were obtained in a total of 17 cases, 10 with MCA aneurysms and seven with ICA aneurysms. In the MCA aneurysm cases, vascular oc-

Table 4 Summary of CBF changes during temporary vascular occlusion

\begin{tabular}{lccc}
\hline \multirow{2}{*}{$\begin{array}{c}\text { Occlusion } \\
\text { site }\end{array}$} & \multirow{2}{*}{$\begin{array}{c}\text { No. of } \\
\text { cases }\end{array}$} & \multicolumn{2}{c}{$\mathrm{CBF}(\mathrm{ml} / 100 \mathrm{gm} / \mathrm{min})$} \\
\cline { 3 - 4 } & - & Preocclusion & During occlusion* \\
\hline MCA & 10 & $31.8 \pm 16.0$ & $10.5 \pm 5.4(34.2 \%)$ \\
ICA & 7 & $45.7 \pm 11.8$ & $25.0 \pm 10.7(55.5 \%)$ \\
\hline
\end{tabular}

${ }^{*}$ Percent of control given in parentheses.

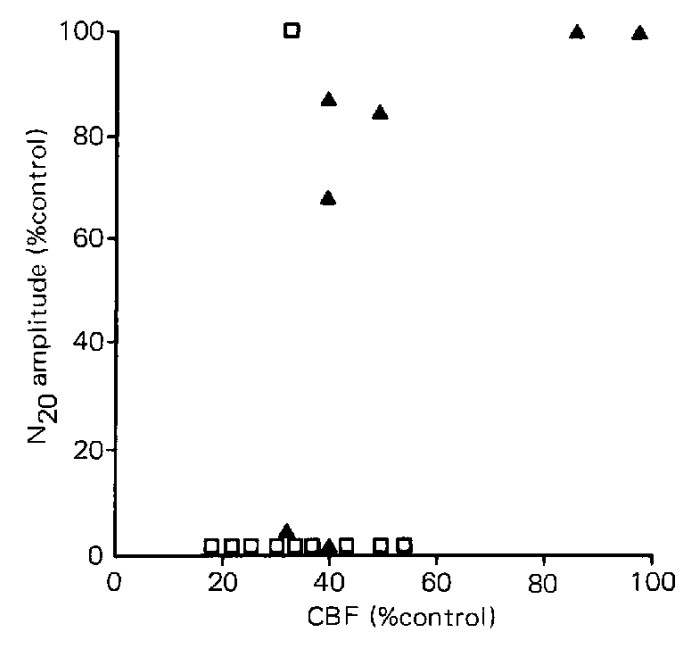

Fig. 5 Relationship between changes in $\mathrm{N}_{20}$ amplitude and $\mathrm{CBF}$ induced by temporary vascular occlusion in cases with MCA aneurysm $(\square, \mathrm{n}=10)$ or ICA aneurysm $(\boldsymbol{\Lambda}, \mathrm{n}=7)$.

clusion reduced the $\mathrm{CBF}$ to $34.2 \%$ of the preocclusion level, but in the ICA aneurysm cases, the CBF decreased to $55.5 \%$ (Table 4). The variation in individuals was much greater in the ICA than MCA 
aneurysm cases (Fig. 5).

SEP attenuation occurred in nine of the $10 \mathrm{MCA}$ aneurysm cases, during which $\mathrm{CBF}$ fell to $18-55 \%$ of the preocclusion level. The case without SEP attenuation demonstrated a $\mathrm{CBF}$ reduction to $33 \%$ during vascular occlusion for 28 minutes. There were fewer ICA aneurysm cases, but some correlation between $\mathrm{CBF}$ and SEP changes was evident. The $\mathrm{N}_{20}$ potential tended to disappear as soon as the CBF decreased to $40 \%$ (Fig. 5).

\section{Discussion}

The $\mathrm{N}_{20}$ component of the median nerve SEP isthought to originate in the cerebral cortex (somatosensory cortex for the upper extremities) or the thalamocortical radiations. Although the origin of the evoked potentials is uncertain, both regions are perfused by the MCA. We found that the $\mathrm{N}_{20}$ component was frequently suppressed during the MCA occlusion and completely disappeared in $75 \%$ of the MCA aneurysm cases. In contrast, only $33 \%$ of the ICA aneurysm cases receiving the ICA occlusion showed $\mathrm{N}_{20}$ suppression. The blood flow to the MCA territory is thought to be influenced by the degree of collateral circulation through the AcomA and posterior communicating artery (PcomA). The CBF monitoring of the present study supports this view. Following MCA occlusion, the CBF uniformly decreased to about $1 / 3$ of the preocclusion level, but following ICA occlusion, the decrease in CBF was between 0 and $70 \%$, with large individual variations. It should be noted, however, that $\mathrm{CBF}$ was measured at one location only. Multiple probes will assess more accurately the effects of occlusion on CBF.

Temporary occlusion of the BA and bilateral PCAs demonstrated $\mathrm{N}_{20}$ attenuation. Since this occlusion reduced the blood flow in the thalamoperforating arteries, etc., the $\mathrm{N}_{20}$ attenuation is thought to be due to disturbances in the thalamocortical neurotransmission. The absence of SEP changes in the few VA cases is probably due to small changes in $\mathrm{CBF}$ in the sensory pathways following unilateral VA occlusion.

It is noteworthy that monitoring the $\mathrm{N}_{20}$ component of the median nerve SEP has little significance in AcomA aneurysm cases requiring anterior cerebral artery (ACA) occlusion. We used stimulation of the upper extremities in a few early cases, but no changes in $\mathrm{N}_{20}$ were observed following ACA occlusion. Stimulation of the lower extremities was tried in seven cases, but again no SEP changes occurred. The SEP from the somatosensory area of the lower extremities was named $\mathrm{P}_{38}$ by Urasaki et al. ${ }^{31}$ This cortical region is clearly fed by ACA branches. In our study, however, no changes in the $P_{38}$ amplitude or latency were demonstrated following ACA occlusion. The reasons for this are thought to be: i) the somatosensory area of the lower extremities is the distal ACA territory, and collateral circulation from the MCA or PCA may be involved when the ACA is occluded; and ii) $\mathrm{P}_{38}$ may reflect activity in subcortical pathways rather than in the primary sensory cortex of the lower extremities. Whatever the cause is, we found that the SEP was inadequate for monitoring cerebral ischemia in the ACA territory. A more suitable technique for monitoring cerebral functions in this region is still required.

The prediction of possible postoperative neurological sequelae is the most important objective of the intraoperative monitoring of cerebral functions. Kidooka et $a l .^{12)}$ found that eight of 13 cases with CCT prolongation by more than $1.2 \mathrm{msec}$ or $\mathrm{N}_{20}$ attenuation developed postoperative symptoms. They considered CCT prolongation by more than $1.2 \mathrm{msec}$ to be critical in temporary vascular occlusion. Momma et $a l .{ }^{17)}$ also considered CCT prolongation and $\mathrm{N}_{20}$ attenuation as danger signals during temporary vascular occlusion. In particular, special caution is required if $\mathrm{N}_{20}$ disappears within 3-4 minutes of vascular occlusion. In our series, $\mathrm{N}_{20}$ disappeared 1 30 minutes after the start of vascular occlusion in 24 cases. With one exception, in 23 cases, $\mathrm{N}_{20}$ peaks reappeared following recirculation by the first measurement (within 1 minute), and returned to the baseline recordings 1-8 minutes (mean $2.6 \mathrm{~min}$ ) in MCA aneurysm cases and 1-20 minutes (mean 4.9 $\mathrm{min}$ ) in ICA aneurysm cases. None of these 23 cases showed postoperative sequelae. The mean length of disappearance of $\mathrm{N}_{20}$ during temporary occlusion (occlusion time - time to $\mathrm{N}_{20}$ loss, Fig. 4) was 10.7 minutes in MCA aneurysm cases and 13.3 minutes in ICA aneurysm cases. Therefore, it is considered that the postoperative outcome is expected to be favorable if the temporary clip is released within about 10 minutes after attenuation of $\mathrm{N}_{20}$. From our results, the permissable temporary occlusion time was thought to be relatively longer than those of the previous reports. ${ }^{11,12)}$ It might be due to the differences of the methods of brain protection. As before mentioned, we routinely use the Sendai cocktail to protect the brain from ischemic damages during temporary occlusion. ${ }^{1,25,26,28,29)}$ However, the most rapid $\mathrm{N}_{20}$ attenuation, within 1 minute of vascular occlusion, occurred in the case in which SEPs did not recover leaving postoperative sequelae (Fig. 4). This case had a broad-based aneurysm at the 
origin of the PcomA from the ICA and received vascular occlusion at four sites: the cervical ICA (17 min), $A_{1}$ segment of the ACA (13 min), $M_{1}$ segment of the MCA (14 min), and PcomA (12 min). Although the $\mathrm{CBF}$ monitoring was not done in this case, it is considered that either severe ischemia in the perforating artery territory or thrombus formation during the temporary occlusion has caused the sequelae.

SEP only monitors the sensory pathways. A more direct method for monitoring motor functions is necessary to prevent postoperative motor deficit. ${ }^{19}$ ) Such techniques are still being developed and are presently more invasive than SEP monitoring. Further technical developments, however, should achieve an effective method for intraoperative monitoring of motor functions.

The present study has found that the $\mathrm{N}_{20}$ component of the median nerve SEP accurately reflects the ischemic state of the MCA territory. This should therefore be useful for intraoperative monitoring of MCA or ICA aneurysm surgery. It is also useful for monitoring the development of stenosis or occlusion of perforating arteries or major vessels secondary to inadequate operative procedures.

\section{References}

1) Abiko H, Suzuki J, Mizoi K, Oba M, Yoshimoto T: Protective effect of phenytoin and its enhanced action by combined administration of mannitol and vitamin E in cerebral ischemia. No To Shinkei 38: 328-335, 1986 (in Japanese)

2) Ausman JI, Diaz FG, Malik GM, Fielding AS, Son CS: Current management of cerebral aneurysm: Is it based on facts or myths? Surg Neurol 24: 625-635, 1985

3) Callow AD, Matsumoto G, Baker D, Watson W: Protection of the high risk carotid endoarterectomy patient by continuous electroencephalography. $J$ Cardiovasc Surg (Torino) 19: 55-64, 1978

4) Carter LP, Raudzens PA, Gaines C, Crowell RM: Somatosensory evoked potentials and cortical blood flow during craniotomy for vascular disease. Neurosurgery 15: 22-28, 1984

5) Collice M, Arena O, Fontana RA, Mola M, Galbiati $\mathrm{N}$ : Role of EEG monitoring and cross-clamping duration in carotid endarterectomy. J Neurosurg 65: $815-$ 819,1986

6) Drake CG, Peerless SJ: Posterior circulation aneurysms, in Kikuchi H, Fukushima T, Watanabe $\mathrm{K}$ (eds): Intracranial Aneurysms: Surgical Timing and Techniques. Niigata, Nishimura, 1986, pp 336-348

7) Friedman WA, Kaplan BL, Day AL, Sypert GW, Curran MT: Evoked potential monitoring during aneurysm operation: Observations after fifty cases.
Neurosurgery 20: 675-687, 1987

8) Hunt WE, Kosnik EJ: Timing and perioperative care in intracranial aneurysm surgery. Clin Neurosurg 21: $79-89,1974$

9) Jabre A, Symon L: Temporary vascular occlusion during aneurysm surgery. Surg Neurol 27: 47-63, 1987

10) Jacobs LA, Brinkman SD, Morrell RM, Shirley JG, Ganji S: Long-latency somatosensory evoked potentials during carotid endarterectomy. Am Surg 49: 338-344, 1983

11) Jones TH, Morawetz RB, Crowell RM, Marcoux FW, FitzGibbon SJ, DeGirolami U, Ojemann RG: Thresholds of focal cerebral ischemia in awake monkeys. I Neurosurg 54: 773-782, 1981

12) Kidooka $M$, Nakasu $Y$, Watanabe $K$, Matsuda $M$, Handa J: Monitoring of somatosensory-evoked potentials during aneurysm surgery. Surg Neurol 27: 69-76, 1987

13) Koshu K, Hirota S, Sonobe M, Takahashi S, Takaku A, Saito T, Ushijima T: Continuous recording of cerebral blood flow by means of thermal diffusion method using Peltier stack. Neurol Med Chir (Tokyo) 27: 724-728, 1987 (in Japanese)

14) Ljunggren B, Säveland H, Brandt L, Kagström E, Rehncrona S, Nillson PE: Temporary clipping during early operation for ruptured aneurysm: Preliminary report. Neurosurgery 12: 525-530, 1983

15) Markand OM, Dilley RS, Moorthy SS, Warren C Jr: Monitoring of somatosensory evoked responses during carotid endoarterectomy. Arch Neurol 41: 375378,1984

16) Mizoi K, Suzuki J, Abiko H, Ogasawara K, Oba M, Yoshimoto T: Experimental study on the reversibility of cerebral ischemia: Residual blood flow and duration of ischemia. Acta Neurochir (Wien) 88: 126134,1987

17) Momma F, Wang AD, Symon L: Effects of temporary arterial occlusion on somatosensory evoked responses in aneurysm surgery. Surg Neurol 27: 343352, 1987

18) Mooiji JJA, Buchthal A, Belopavlovic M: Somatosensory evoked potential monitoring of temporary middle cerebral artery occlusion during aneurysm operation. Neurosurgery 21: 492-496, 1987

19) Oro J, Levy J: Motor evoked potential as a monitor of middle cerebral artery ischemia and stroke. Neurosurgery 20: 192-193, 1987

20) Rampil IJ, Correll JW, Rosenbaum SH, Quest DO, Holzer JA: Computerized electroencephalogram monitoring and carotid artery shunting. Neurosurgery 13: 276-279, 1983

21) Russ W, Friedrich FW, Hempelmann G: Intraoperative somatosensory evoked potentials as a prognostic factor of neurologic state after carotid endoarterectomy. Thorac Cardiovasc Surg 33: 392-396, 1985

22) Sharbrough FW, Messick JM, Sundt TM: Correlation of continuous electroencephalograms with 
cerebral blood flow measurements during carotid endoarterectomy. Stroke 4: 674-683, 1973

23) Sundt TM: The ischemic tolerance of neural tissue and the need for monitoring and selective shunting during carotid endoarterectomy. Stroke 14: 93-98, 1983

24) Sundt TM, Sharbrough FW, Anderson RE, Michenfelder JD: Cerebral blood flow measurements and electroencephalograms during carotid endarterectomy. J Neurosurg 41: 310-320, 1974

25) Suzuki J, Fujimoto S, Mizoi K, Oba M, Yoshimoto $T$ : The protective effect of combined administration of antioxidants and perfluorochemicals on cerebral ischemia. Stroke 15: 672-679, 1984

26) Suzuki J, Kodama N, Yoshimoto T, Mizoi K: Ultraearly surgery of intracranial aneurysms. Acta Neurochir (Wien) 63: 185-191, 1982

27) Suzuki J, Mizoi K, Yoshimoto T: Bifrontal interhemispheric approach to aneurysms of the anterior communicating artery. $J$ Neurosurg 64: 183190, 1986

28) Suzuki J, Yoshimoto $T$ : The effect of mannitol in prolongation of permissible occlusion time of cerebral artery: Clinical data of aneurysm surgery. Neurosurg Rev 1: 13-19, 1979

29) Suzuki J, Yoshimoto T, Kayama T: Surgical treatment of middle cerebral artery aneurysms. $J$ Neurosurg 61: 17-23, 1984
30) Symon L, Wang AD, Costa e Silva IE, Gentili F: Perioperative use of somatosensory evoked responses in aneurysm surgery. I Neurosurg 60: 269-275, 1984

31) Urasaki E, Matsukado $Y$, Wada S, Nagahiro S, Yadomi C: Origin of the early components of somatosensory evoked potentials by the posterior tibial nerve stimulation. A comparative study to median nerve stimulation in clinical cases. No To Shinkei 37: 945-955, 1985 (in Japanese)

32) Wang AD, Cone JC, Symon L, Costa e Silva IE: Somatosensory evoked potential monitoring during the management of aneurysmal SAH. J Neurosurg 60: 264-268, 1984

33) Yamagata S, Kikuchi H, Karasawa J, Ihara I, Nagata I, Naruo Y, Takeuchi S, Shishido H, Kaneko M, Ito M, Hashimoto K, Minamikawa J, Miyamoto S: Monitor system for local cerebral blood flow. Experimental study of CBF measurement by thermal diffusion using a flow probe with a Peltier stack. Neurol Med Chir (Tokyo) 26: 195-200, 1986 (in Japanese)

Address reprint requests to: K. Mizoi, M.D., Department of Neurosurgery, Kohnan Hospital, 4-20-1 Nagamachi-minami, Sendai 982, Japan. 